\title{
Mouse sperm capacitation assessed by kinetics and morphology of fertilization in vitro
}

\author{
Lynn R. Fraser \\ Department of Human Biology, Chelsea College, Manresa Road, London SW3 6LX, U.K.
}

\begin{abstract}
Summary. Epididymal mouse spermatozoa were preincubated for periods of 5-120 min and then tested for their ability to penetrate freshly ovulated eggs synchronously and rapidly. When zona-intact eggs were used, only suspensions preincubated for $120 \mathrm{~min}$ gave consistently high rates of fertilization, but suspensions preincubated for 30 min were functionally equivalent to those incubated for $120 \mathrm{~min}$ when used with zona-free eggs; the only major observable differences were a 15-min lag in sperm-egg interaction and an increased incidence of asynchrony with multiple sperm penetrations. A morphological study of sperm-egg interactions using zona-intact eggs indicated that, within 35 min of gamete mixing, egg microvilli could be detected by SEM in association with the fertilizing sperm head. Using conventional light microscopic examination of fixed and stained preparations, initial stages of sperm head decondensation could be detected in the majority of eggs after 45-60 min and the process was essentially completed, with the egg at the telophase-second polar body stage of meiosis II, after $75 \mathrm{~min}$. Similar kinetics were observed with sperm concentrations of $10^{5}$ and $10^{6} / \mathrm{ml}$. The time required for penetration by capacitated sperm suspensions is therefore relatively short and the most accurate information regarding state of capacitation and rate of sperm penetration can be obtained by choosing an appropriately short interval for sperm-egg interaction before assessment.
\end{abstract}

\section{Introduction}

In recent years, mammalian in-vitro fertilization systems have been used extensively to examine requirements for successful fertilization, particularly those needed for sperm capacitation without which spermatozoa are not competent to penetrate the zona pellucida and to fuse with the egg plasma membrane. It is generally accepted that capacitation prepares the potentially fertilizing spermatozoon to undergo the acrosome reaction (Bedford, 1970), but another factor which plays an equally important role in penetration of the zona pellucida is sperm motility. In the absence of the characteristic whiplash motility, which has been observed in numerous species around the time spermatozoa become demonstrably capacitated (e.g. hamster: Yanagimachi, 1970; guinea-pig: Yanagimachi, 1972; ram: Shams-Borhan \& Harrison, 1981; mouse: Fraser, 1977), penetration of the zona pellucida is inhibited although fusion with zona-free eggs is still possible (Fraser, 1981).

A population of spermatozoa which contains a reasonable proportion of capacitated cells will exhibit rapid and synchronous penetration of zonae and fusion with egg plasma membranes (e.g. Fraser, 1981, 1982b). The early stages of sperm head fusion with the egg and nuclear decondensation are easily recognizable and occur over a relatively short and definable time span. Once pronuclear formation has begun, it is quite likely that some asynchrony develops and the fact that the pronuclear stage lasts for about $12-16 \mathrm{~h}$ (Donahue, 1972) makes it very difficult to 
discriminate between eggs which were penetrated soon after mixing with spermatozoa and those penetrated later. It is therefore impossible to determine whether spermatozoa were capacitated at the time eggs were introduced.

In the present experiments, designed to clarify some of these points and to demonstrate the kinetics of mouse sperm-egg interactions, an in-vitro fertilization system which has proved to be highly efficient and reliable was used.

\section{Materials and Methods}

\section{Medium}

The medium used in all experiments was a modified Tyrode's solution (Fraser \& Drury, 1975) from which pyruvate and lactate were omitted; additional $\mathrm{NaCl}(25 \mathrm{mM})$ was included to maintain total osmolality and BSA ( $4 \mathrm{mg} / \mathrm{ml}$; Armour, Eastbourne, Sussex, U.K.) was also present. All incubations were carried out at $37^{\circ} \mathrm{C}$ in $30-\mathrm{mm}$ plastic dishes (Sterilin, Teddington, Middx., U.K.); the medium was overlaid with sterile (autoclaved) liquid paraffin (Boots, Nottingham, U.K.). The gas phase was $5 \% \mathrm{CO}_{2}-5 \% \mathrm{O}_{2}-90 \% \mathrm{~N}_{2}$.

\section{In-vitro fertilization}

Mature TO females ( $>8$ weeks) were induced to superovulate by i.p. injections of $7 \cdot 5$ i.u. PMSG (Gestyl: Organon, Morden, Surrey, U.K.) and, 48-54 h later, 5 i.u. hCG (Pregnyl: Organon). Unfertilized eggs were recovered $14 \mathrm{~h}$ after hCG injection. Intact eggs were released directly from oviducts into sperm suspensions and therefore possessed cumulus cells. Zona-free eggs were prepared by first removing cumulus cells with a hyaluronidase solution ( $300 \mathrm{units} / \mathrm{ml}$; bovine testes Type I: Sigma, London, U.K.), washing and then treating with a pronase solution $(0.04 \%$ : Koch-Light, Colnbrook, Bucks., U.K.) which had been prepared and dialysed as described previously (Fraser, 1981). Before the zonae were totally solubilized, the eggs were removed to enzyme-free medium for final removal of this layer and then washed in enzyme-free medium before addition to sperm suspensions. When sperm suspensions preincubated for various periods were tested on the same day, hCG was injected asynchronously to ensure that eggs used for any single time point were recovered $14 \mathrm{~h}$ after $\mathrm{hCG}$.

The epididymides were removed from 2 mature TO males ( $>8$ weeks) and the contents of 1 cauda epididymidis from each animal were released into $1 \mathrm{ml}$ medium. Suspensions were preincubated for a total of $120 \mathrm{~min}$, with $0 \cdot 1-\mathrm{ml}$ aliquants being taken at the times noted below and diluted 10 -fold to a concentration of $1-2 \times 10^{6} \mathrm{cells} / \mathrm{ml}$; eggs were added to $300-\mu 1$ droplets of the diluted suspension.

Series $I$. Sperm suspensions were preincubated for 5, 30,60 and $120 \mathrm{~min}$ and then tested for their ability to fertilize intact and zona-free eggs. Only intact eggs were used for the 60 -min treatment group. Since it was logistically impossible to examine all timings on the same day, 2 or 3 were examined on any one day, always including a 120 -min preincubation which served as the control group for comparison; at least 5 experiments were carried out for each time. After 75 min eggs were fixed and assessed as described below.

Series II. Sperm suspensions were preincubated for 5, 30 and $120 \mathrm{~min}$ and zona-free eggs were added; intact and zona-free eggs were examined in the 120-min group. Eggs were fixed after 30, 45, 60 and $75 \mathrm{~min}$ and assessed as below. At least 3 experiments were carried out for each of the 3 preincubation times, with the 5- and 120-min groups being examined on the same days and the 30 min ones on different days. Comparisons were made within and not between timing groups.

Series $I I I$. Zona-free eggs were added to sperm suspensions preincubated for $120 \mathrm{~min}$ and then fixed at $75 \mathrm{~min}$ and $4 \mathrm{~h}$.

Series $I V$. Sperm suspensions were preincubated for $120 \mathrm{~min}$ and then the initial diluted sample of approximately $10^{6}$ cells $/ \mathrm{ml}$ was diluted again 10 -fold to give $10^{5}$ cells $/ \mathrm{ml}$. The $2 \mathrm{sperm}$ 
concentrations were then tested with intact eggs as described for Series $I$ in 4 experiments. Eggs used with the lower sperm concentration required hyaluronidase treatment to complete cumulus cell dispersal before fixation.

Series $V$. Morphological features of the early stages of sperm-egg interaction were examined using light microscopy, scanning electron microscopy (SEM) and transmission electron microscopy (TEM), with emphasis on intact rather than zona-free eggs. For light microscopy, eggs were fixed in neutral buffered formalin and stained with aceto-orcein as described below. Eggs were examined $30,45,60$ and $75 \mathrm{~min}$ after introduction to sperm suspensions preincubated for $120 \mathrm{~min}$, i.e. those which give consistently high rates of fertilization. For SEM and TEM, eggs were fixed in glutaraldehyde $(2.5 \%$ in 0.1 M-cacodylate buffer, $\mathrm{pH} 7.4) 35,45,55,65$ and $75 \mathrm{~min}$ after introduction to sperm suspensions. A few of these were examined with light microscopy to confirm that fertilization rates were high. For SEM, eggs were next treated with pronase to remove zonae and then again with glutaraldehyde to stop proteolytic digestion. All eggs were washed in buffer, post-fixed in $1 \%$ osmium tetroxide and dehydrated in graded alcohols. For SEM, eggs were then placed onto filter paper (No. 1, Whatman, Maidstone, Kent, U.K.) and acetone was added. Specimens were critical-point dried using $\mathrm{CO}_{2}$ (dryer model E3000; Polaron, Watford, Herts., U.K.), coated with gold-palladium in a Polaron E5100 sputter coater and examined in a Philips SEM 501B. For TEM, fixed and dehydrated eggs were embedded in Epon. Sections were cut on a Reichert ultramicrotome, stained with uranyl acetate and lead citrate and then examined with a Philips $301 \mathrm{G}$ electron microscope. Eggs from the same fixation groups were used for both sets of procedures; about 60 eggs were examined, primarily with SEM.

\section{Routine assessment}

Just before the designated fixing time, eggs were transferred from sperm suspensions to small droplets of medium under oil and, at the appropriate time, dishes were flooded with neutral buffered formalin ( $4 \%$ formaldehyde). Eggs were then transferred in a minimal volume of formalin to a small drop of aceto-orcein $(0.75 \%$ in $45 \%$ acetic acid) on a microscope slide, another small drop of stain was added and then a coverslip applied. Eggs were considered to be fertilized if they had resumed meiosis II and possessed a decondensing sperm head. In addition to determining the proportion of eggs fertilized, the proportion of eggs with maximal nuclear development for a 75min sperm-egg incubation, i.e. eggs at telophase-second polar body and sperm heads fully decondensed, was calculated to measure the rate at which sperm penetration had occurred. The incidence and degree of polyspermy were assessed in zona-free eggs.

After preincubation, sperm suspensions were diluted and assessed for the expression of the whiplash motility pattern associated with fertilizing ability (Fraser, 1977).

\section{Statistical analysis}

Results were analysed using Cochran's test for combination of $2 \times 2$ contingency tables (Snedecor \& Cochran, 1967). This permitted comparisons within individual experiments, since not all timings used in Series I could be carried out on the same day, and also allowed for any variation in kinetics amongst sperm suspensions used on different days and for differences in sample sizes.

\section{Results}

\section{Series I}

For statistical evaluation, the results obtained with the shorter precincubations were compared with those from the 120 -min preincubation. There were striking differences in the proportions of intact eggs fertilized (Table 1), with the 5-and 30-min sperm preincubation groups showing signifi- 
Table 1. Fertilization in vitro of zona-intact and zona-free mouse eggs by sperm suspensions preincubated for 5-120 min before addition of eggs

\begin{tabular}{|c|c|c|c|}
\hline $\begin{array}{c}\text { Sperm } \\
\text { preincubation time } \\
\text { (min) }\end{array}$ & \pm Zona & $\begin{array}{c}\text { Eggs } \\
\text { fertilized }(\%) \\
\text { [range] }\end{array}$ & $\begin{array}{c}\text { Maximal nuclear } \\
\text { development } \dagger, \% \\
\text { (range) }\end{array}$ \\
\hline \multirow[t]{2}{*}{5} & + & $\begin{array}{c}4 / 134(3 \cdot 0)^{* * *} \\
{[0-8]}\end{array}$ & $0^{* * *}$ \\
\hline & - & $\begin{array}{c}76 / 81(93 \cdot 8) \\
{[71-100]}\end{array}$ & $\begin{array}{c}26 \cdot 3^{* * * *} \\
(0-83)\end{array}$ \\
\hline 30 & $\begin{array}{l}+ \\
-\end{array}$ & $\begin{array}{c}31 / 67(46 \cdot 3)^{* * * *} \\
{[30-53]} \\
37 / 38(97 \cdot 4) \\
{[83-100]}\end{array}$ & $\begin{array}{c}25 \cdot 8^{* * *} \\
(0-67) \\
100\end{array}$ \\
\hline 60 & + & $\begin{array}{c}106 / 147(72 \cdot 1) \\
{[23-94]}\end{array}$ & $\begin{array}{c}51 \cdot 9^{*} \\
(40-87)\end{array}$ \\
\hline 120 & $\begin{array}{l}+ \\
-\end{array}$ & $\begin{array}{c}101 / 117(86 \cdot 3) \\
{[50 ; 84-100]} \\
148 / 148(100)\end{array}$ & $\begin{array}{c}85 \cdot 2 \\
(80-100) \\
99 \cdot 3 \\
(88-100)\end{array}$ \\
\hline
\end{tabular}

$\dagger$ Eggs at telophase-second polar body stage; sperm heads fully decondensed.

Compared with 120 -min group, ${ }^{*} P<0.025 ;{ }^{* * *} P<0.001$.

cantly lower proportions of fertilized eggs $(P<0.001)$. Although the mean figure for a $60-\mathrm{min}$ preincubation was lower than that for the 120 -min group, this was not statistically significant. Using sperm and egg nuclear development as indicators of rate of sperm penetration, significantly slower rates were observed in all groups: 5 and $30 \mathrm{~min}, P<0.001 ; 60 \mathrm{~min}, P<0.025$. Only the 120min suspensions promoted consistently (except for 1 exp., see Table 1) high levels of fertilization (mean, 86.3\%) and rapid, synchronous penetration (85.2\% at maximal stages).

With the zona-free eggs, only the 5 -min preincubation group showed lower proportions for fertilization and rate of penetration $(P<0.001)$. The values for the $30-$ and 120 -min suspensions were not significantly different. A similar pattern was noted in the incidence and degree of polyspermy detected in zona-free eggs (Table 2). Fewer than half the penetrated eggs in the 5-min preincubation group were polyspermic $(P<0.001)$ and the majority of these were dispermic. In contrast, high incidences of polyspermy were noted with 30 - and 120 -min suspensions and more eggs had 3 or more fertilizing spermatozoa. In the 30 -min preincubation group, a high proportion of eggs had asynchronously decondensing sperm heads, while in the majority of eggs in the other groups, multiple fertilizing spermatozoa were developing synchronously, e.g. all just beginning to decondense or all fully decondensed. When asynchrony was noted, at least 1 sperm head was fully decondensed and the other(s) lagged behind.

Table 2. Incidence and degree of polyspermy in zona-free mouse eggs fertilized in vitro by sperm suspensions preincubated for 5-120 min before addition of eggs

\begin{tabular}{ccccrr}
\hline \multirow{2}{*}{$\begin{array}{c}\text { Sperm } \\
\text { preincubation } \begin{array}{c}\text { Nime } \\
(\text { min) }\end{array}\end{array}$} & No. of polyspermic & \multicolumn{2}{c}{ No. of spermatozoa/egg, \% } & \\
\cline { 3 - 4 } & eggs/total (\%) & 2 & 3 & $4+$ & $\begin{array}{c}\text { Asynchronous } \\
\text { sperm } \dagger, \%\end{array}$ \\
\hline 5 & $32 / 76(42 \cdot 1)^{* * *}$ & $96 \cdot 9$ & $3 \cdot 1$ & & $3 \cdot 1$ \\
30 & $36 / 47(76 \cdot 9)$ & $77 \cdot 8$ & $16 \cdot 7$ & $5 \cdot 6$ & $22 \cdot 2$ \\
120 & $127 / 148(85 \cdot 8)$ & $51 \cdot 2$ & $31 \cdot 5$ & $17 \cdot 3$ & $0 \cdot 8$ \\
\hline
\end{tabular}

† Sperm heads at different stages of decondensation within single egg.

Compared with 120 -min group, ${ }^{* * *} P<0.001$. 
In all experiments, expression of whiplash motility was greatest (maximum subjective assessment of +++ ) in 120-min samples. Preincubations of 5 and $30 \mathrm{~min}$ led to practically no detectable motility of this type ( - to \pm ), while some spermatozoa $(+$ to ++ ) in the 60-min group exhibited this motility.

\section{Series $I I$}

The results in Table 3 relate only to the 45-, 60- and 75-min intervals to fixation because very few eggs showed unequivocal signs of fertilization when examined with the light microscope after 30 min. The sperm-zona-free egg interaction occurred most rapidly when sperm suspensions had been preincubated for $120 \mathrm{~min}$, with the majority of eggs reaching maximal stages within $60 \mathrm{~min}$. Sperm penetration and decondensation were slower in the 5- and 30-min preincubated suspensions. Intact eggs mixed with spermatozoa preincubated for 120 min reached maximal fertilization and development by $75 \mathrm{~min}$, but lagged slightly behind the zona-free eggs mixed with the same suspensions; this lag presumably represents, at least in part, zona penetration (Table 3 ).

Table 3. Incidence and degree of polyspermy in zona-free mouse eggs fertilized in vitro by sperm suspensions preincubated 5-120 min and fixed $45-75 \mathrm{~min}$ after gamete mixing

\begin{tabular}{|c|c|c|c|c|c|c|c|c|}
\hline \multirow{2}{*}{$\begin{array}{c}\text { Sperm } \\
\text { preincubation } \\
\text { time (min) }\end{array}$} & \multirow{2}{*}{$\begin{array}{l}\text { Interval to } \\
\text { fixation } \\
\text { (min) }\end{array}$} & \multirow{2}{*}{$\begin{array}{l}\text { Eggs } \\
\text { fertilized, } \%\end{array}$} & \multirow{2}{*}{$\begin{array}{c}\text { Maximal } \\
\text { nuclear } \\
\text { development } \dagger, \%\end{array}$} & \multirow{2}{*}{$\begin{array}{l}\text { Polyspermic } \\
\text { eggs, } \%\end{array}$} & \multicolumn{3}{|c|}{$\begin{array}{c}\text { No. of spermatozoa/ } \\
\text { egg, } \%\end{array}$} & \multirow{2}{*}{$\begin{array}{c}\text { Asynchronous } \\
\text { sperm. } \neq, \%\end{array}$} \\
\hline & & & & & 2 & 3 & $4+$ & \\
\hline \multirow[t]{3}{*}{5} & 45 & 1/67, & 0 & 0 & 0 & 0 & 0 & 0 \\
\hline & 60 & $18 / 64, \quad 28$ & 0 & $55 \cdot 5$ & $70 \cdot 0$ & $30 \cdot 0$ & 0 & 0 \\
\hline & 75 & $61 / 66, \quad 92$ & 23 & $45 \cdot 9$ & $96 \cdot 4$ & $3 \cdot 6$ & 0 & 3.6 \\
\hline \multirow[t]{3}{*}{30} & 45 & $23 / 38, \quad 61$ & 0 & $56 \cdot 5$ & $92 \cdot 3$ & $7 \cdot 7$ & 0 & 0 \\
\hline & 60 & $19 / 19,100$ & 21 & 78.9 & $80 \cdot 0$ & $13 \cdot 3$ & $6 \cdot 7$ & $20 \cdot 0$ \\
\hline & 75 & $26 / 26,100$ & 93 & 76.9 & 75.0 & $15 \cdot 0$ & $10 \cdot 0$ & $30 \cdot 0$ \\
\hline \multirow[t]{3}{*}{120} & 45 & $\begin{array}{c}53 / 53,100 \\
(27 / 58,47)^{*}\end{array}$ & $\begin{array}{c}6 \\
(0)^{*}\end{array}$ & 84.9 & $62 \cdot 2$ & $24 \cdot 4$ & $13 \cdot 3$ & 0 \\
\hline & 60 & $\begin{array}{c}42 / 42,100 \\
(40 / 47,85)^{*}\end{array}$ & $\begin{array}{l}67 \\
(12)^{*}\end{array}$ & $88 \cdot 1$ & $73 \cdot 0$ & 18.9 & $8 \cdot 1$ & $5 \cdot 4$ \\
\hline & 75 & $\begin{array}{c}40 / 40,100 \\
(39 / 42,93)^{*}\end{array}$ & $\begin{array}{l}100 \\
(87)^{*}\end{array}$ & 95.0 & $42 \cdot 1$ & $39 \cdot 5$ & $18 \cdot 4$ & 0 \\
\hline
\end{tabular}

* Values for zona-intact eggs.

$\dagger$ Eggs at telophase-second polar body stage; sperm heads fully decondensed.

‡ Sperm heads at different stages of decondensation within single egg.

The incidence and degree of polyspermy observed in the 3 groups was very similar to that found in Series I, with a relatively low incidence, primarily dispermy, in the 5-min group and much higher incidences with higher degrees of polyspermy in the 30- and 120-min groups (Table 3). Within groups, there was no significant difference in the degree of polyspermy over the assessment period. Again, the suspensions preincubated for $30 \mathrm{~min}$ were associated with asynchronously decondensing sperm heads in eggs with multiple penetrations. Statistical comparisons were made only within groups.

\section{Series III}

The proportion of penetrated zona-free eggs was similar after $75 \min (114 / 115,99 \cdot 1 \%)$ and $4 \mathrm{~h}$ $(113 / 113,100 \%)$. There was no significant difference in the incidence $(62.2$ and $65.5 \%)$ or degree ( 81.7 and $79.7 \%$ dispermic) of polyspermy in the two groups, respectively, although $17 \%$ of the sperm heads observed in eggs fixed after $4 \mathrm{~h}$ were contained in cytoplasmic blebs. 


\section{Series IV}

When the rate of fertilization was assessed using suspensions containing $10^{6}$ and $10^{5}$ spermatozoa/ml, there were no significant differences in the proportion of eggs fertilized $-10^{6} / \mathrm{ml}$, $78 / 87(90 \%) ; 10^{5} / \mathrm{ml}, 41 / 47(87 \%)-$ or in the rate of penetration as determined by the proportion of fertilized eggs showing maximal nuclear development $\left(10^{6} / \mathrm{ml}, 92 \% ; 10^{5} / \mathrm{ml}, 93 \%\right)$ even though cumulus cell dispersal was incomplete in the latter.

\section{Series $V$}

The first time point at which a decondensing sperm head could be detected reliably in intact eggs with light microscopy was $45 \mathrm{~min}$ after gamete mixing and the majority of heads at this time were just beginning to decondense (Pl. 1, Fig. 1). Stain is taken up only in the region of fusion which appears as a dark line (red in the original specimen) at the posterior region of the sperm head. The line of fusion then proceeds anteriorly (PI. 1, Fig. 3), usually along the convex part of the head, in zipper-like fashion until only the anterior tip (perforatorium: Austin, 1961) remains. When the sperm head is fully decondensed, often only the neck is stained red and chromatin stains a uniform pink (Pl. 1, Fig. 5). Fully decondensed heads are almost always found in eggs at telophase (P1. 1, Fig. 5), half-decondensed heads are usually found only in eggs at late anaphase and the earliest sperm head stages can be seen in eggs at all stages of anaphase.

By using SEM techniques it was possible to detect earlier stages of fertilizing sperm-egg interactions, i.e. within $35 \mathrm{~min}$ of gamete mixing. In the majority of eggs examined, the sperm head was lying flat on the egg and microvilli from the egg surface were contacting the posterior region of the head (Pl. 1, Fig. 2). In eggs fixed at $45 \mathrm{~min}$, the fertilizing sperm head was more difficult to pick out, being extensively and often totally covered by a thin layer of egg cytoplasm, although it was often possible to detect the outline of the head (Pl. 1, Fig. 4). When eggs fixed at 45 min were sectioned and examined, the overlying egg cytoplasm could be clearly seen, while the bulk of the sperm head appeared to have all membranes intact except for the area of decondensation in the posterior region of the head (Pl. 2, Figs 8 \& 9). The most anterior head region was also within the egg cytoplasm but often with a greater gap between the egg and intact sperm membranes (Pl. 2, Fig.

\section{PLATE 1}

Figs 1, 3 and 5. Specimens were fixed in neutral-buffered formalin, stained with aceto-orcein and examined by light microscopy.

Figs 2, 4 and 6. Specimens were fixed in glutaraldehyde, processed as described in the text and examined by scanning electron microscopy. In all figures, the fertilizing sperm head is indicated by a large arrow.

Fig. 1. Typical appearance of mouse sperm head in eggs fixed after $45-60 \mathrm{~min} . \times 1000$.

Fig. 2. Initial stages of sperm head : egg microvilli interaction in an egg fixed after $35 \mathrm{~min}$. $\times 8500$.

Fig. 3. Typical appearance of sperm head in eggs fixed after $60 \mathrm{~min}$; small arrow indicates a non-fusing sperm head on the surface of the egg. $\times 1000$.

Fig. 4. Fertilizing sperm head in egg fixed after $45 \mathrm{~min}$; note proximity to the microvilli-free area of the meiotic spindle. $\times 750$.

Fig. 5. Typical appearance of the sperm head in an egg fixed after $75 \mathrm{~min} . \times 600$.

Fig. 6. Fertilizing sperm head in an egg fixed after $65 \mathrm{~min}$; note the initial stages of polar body extrusion at the top of the egg. $\times 750$. 


\section{PLATE 1}
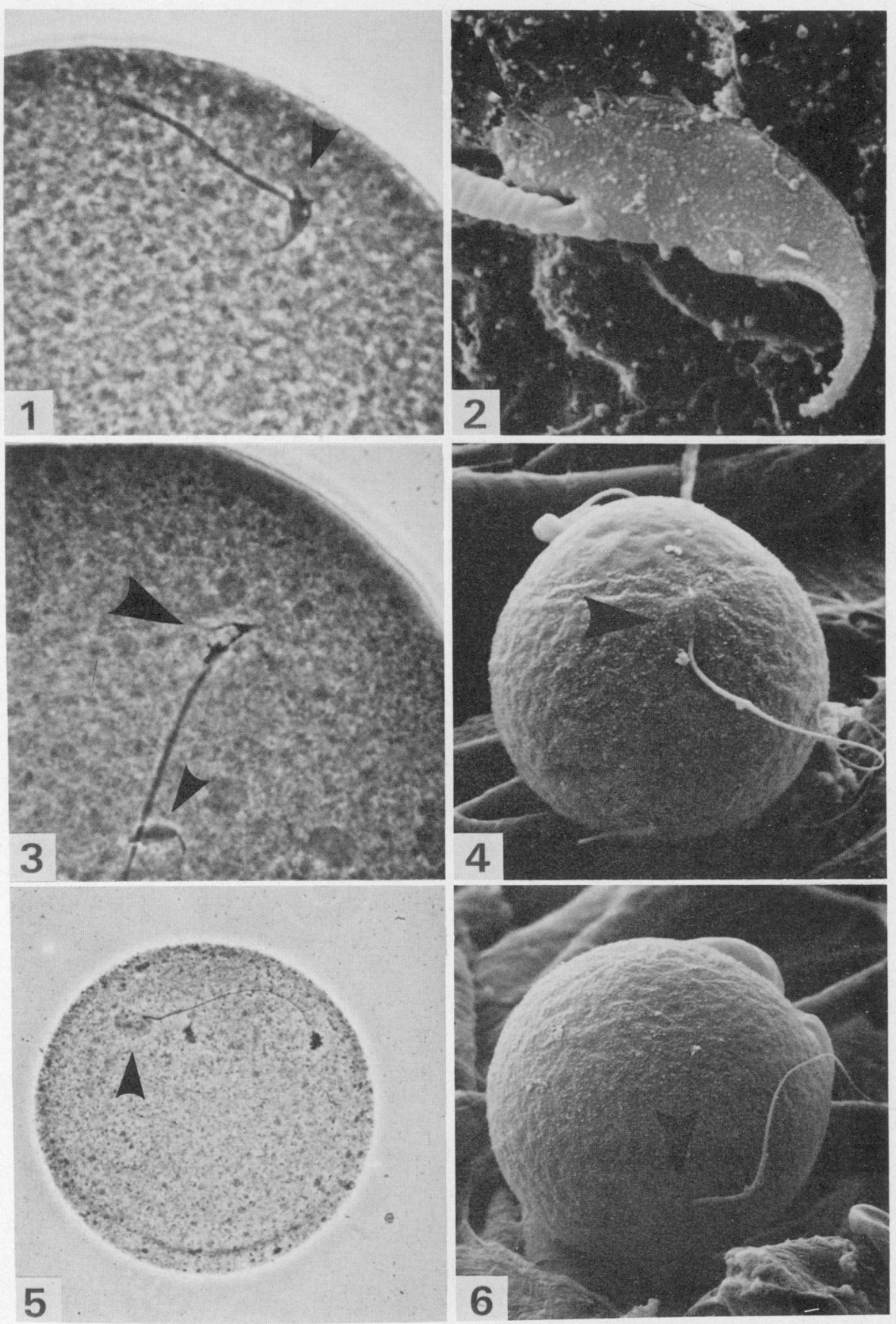
PLATE 2
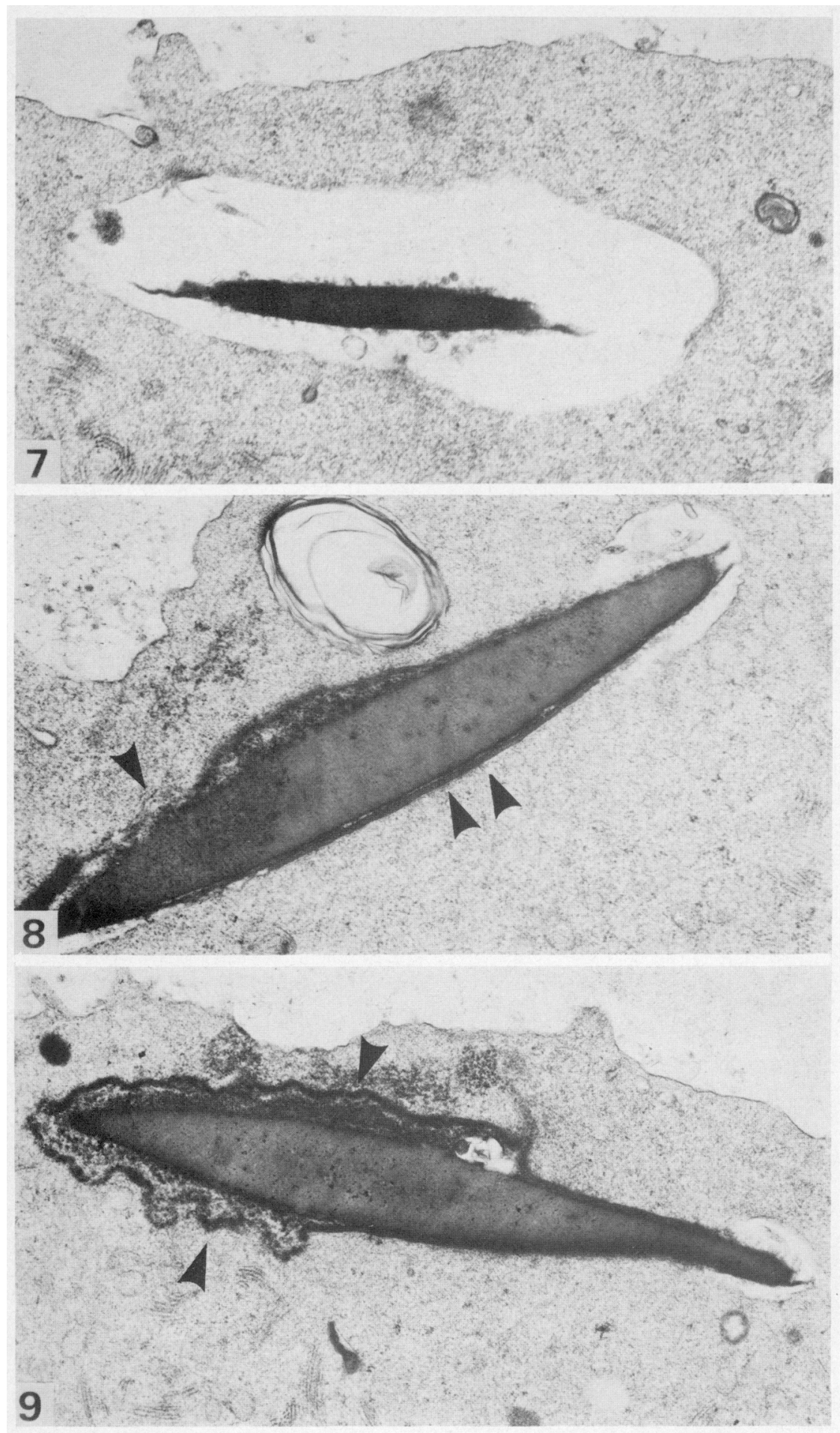
7). By this time (45 $\mathrm{min}$ ), eggs with a decondensing sperm head were essentially devoid of cortical granules. By $75 \mathrm{~min}$, sperm head incorporation had been completed, although the tail remained outside the egg (P1. 1, Fig. 6).

\section{Discussion}

These data indicate that the most consistent, rapid and synchronous fertilization of mouse eggs was obtained with epididymal sperm suspensions which had been preincubated for $120 \mathrm{~min}$; the use of shorter intervals resulted in increased variability between experiments both in proportion of eggs fertilized and rate of sperm penetration. Successful fertilization depends on the relative proportions of capacitated and uncapacitated spermatozoa in the population at any one time. The rate at which an individual spermatozoon becomes capacitated cannot be determined with the present experimental techniques, but individual suspensions vary in the length of preincubation required for the population to support optimal fertilization (see range of results, Table 1); after 120-min preincubation, however, all suspensions of spermatozoa from TO mice have reached this state. It is concluded, therefore, that studies undertaken to examine effects of experimental treatments on capacitation and subsequent fertilization need to be carefully designed to permit accurate interpretation. If the effect may be interference with capacitation, the untreated control sperm suspensions must be fully capacitated when eggs are added. If effects might accelerate capacitation, a relatively short preincubation of spermatozoa is more suitable, and striking differences can often be observed (e.g. Fraser, 1979, 1981, 1982b). Both possibilities can be examined by using a short and a long preincubation for comparison (Fraser, 1979, 1981; present study).

If sufficient numbers of capacitated spermatozoa are present at the time eggs are introduced, sperm fusion with intact eggs can be detected unequivocally by conventional light microscopy within 45-60 min. Since full decondensation of sperm nuclear material is completed within $75 \mathrm{~min}$ in most specimens, the entire process of fusion and decondensation requires approximately $30 \mathrm{~min}$. The use of long intervals for sperm-egg incubation (e.g. 3-5 h) will therefore make the assessment of whether spermatozoa were capacitated after initial treatment more difficult and reduce information about the rate of sperm penetration.

In the present study, high proportions of fertilized eggs, both zona-intact and zona-free, were obtained with 120-min preincubated suspensions. Acrosome loss was not determined in these experiments since similar assessments under the same conditions have been made previously and been shown to be consistent (e.g. Fraser, $1981: 5 \mathrm{~min}$ samples, 6.9\% acrosome-free; $30 \mathrm{~min}, 12.4 \%$; $120 \mathrm{~min}, 37.7 \%$; Fraser, $1982 \mathrm{~b} ; 30 \mathrm{~min}, 7 \cdot 6 \% ; 120 \mathrm{~min}, 32 \cdot 3 \%$; the 5 -min values represent the background incidence. While suspensions which exhibit very low acrosome loss and a low

\section{PLATE 2}

The figures are taken from different regions of the same fertilizing sperm head in an egg fixed after $45 \mathrm{~min}$, processed as described in the text and examined by transmission electron microscopy.

Fig. 7. Anterior tip of sperm head surrounded by egg cytoplasm but not in direct contact. $\times 20500$.

Fig. 8. Middle region of the sperm head where contact with the egg cytoplasm is more extensive but the area of fusion is limited (single arrow); the equatorial segment appears to be intact (double arrow). $\times 27000$.

Fig. 9. Posterior region of the sperm head where fusion is most extensive (single arrows). $\times 18000$. 
incidence of whiplash motility (e.g. $30 \mathrm{~min}$ ) were relatively infertile with zona-intact eggs, they were highly fertile once zonae were removed. In spite of a slight lag in sperm penetration compared with the 120 -min group, the incidence of polyspermy in eggs fertilized by the 30 -min preincubated spermatozoa was very high (Tables $2 \& 3$ ) and did not differ significantly from that observed in the 120-min group. Fraser (1982a) showed that a sperm concentration of $10^{6}$ cells $/ \mathrm{ml}$ yielded $83 \%$ polyspermic eggs compared with $38 \%$ for $10^{5}$ cells $/ \mathrm{ml}$ of the same suspension. It can therefore be deduced that a substantial proportion of spermatozoa in the 30 -min group were 'fit' even though few would have been acrosome-free at the time eggs were introduced. Since it is generally agreed that spermatozoa must undergo the acrosome reaction even before fusing with zona-free eggs, high levels of fertilization and polyspermy would not be predicted on the basis of the above acrosomeloss data. These results therefore suggest that the spermatozoa might be responding to some influence exerted by the eggs themselves, i.e. the eggs may be specifically inducing the acrosome reaction, as proposed by others (see Meizel, 1978). Another source for such a proposed stimulus is the zona pellucida (see Florman \& Storey, 1982), although the present study indicates a much more effective interaction between 30 -min preincubated spermatozoa and eggs in the absence of the zona than in its presence.

The performance of 30 -min preincubated spermatozoa with zona-free eggs would appear to exceed their potential as assessed by motility, overt acrosome-loss and fertility with intact eggs. The spermatozoa in this group were also unusual in that a relatively high proportion of polyspermic eggs had asynchronously decondensing sperm heads (Tables $2 \& 3$ ). This is unlikely to be attributed to the egg cytoplasm, since all eggs were obtained $14 \mathrm{~h}$ after hCG and, furthermore, very little asynchrony was associated with the sperm suspensions preincubated for $120 \mathrm{~min}$. A possible explanation is that, although spermatozoa after $30 \mathrm{~min}$ preincubation were competent to undergo the acrosome reaction, possibly in response to an egg-derived stimulus, they were less competent to respond to egg signals associated with nuclear decondensation. Perhaps complete capacitation involves much more than just the promotion of the acrosome reaction (Bedford, 1970).

The kinetics of sperm penetration presented here are consistent with those reported in other studies using different strains of mice (Toyoda, Yokoyama \& Hosi, 1971; Fukuda \& Chang, $1978 \mathrm{a}, \mathrm{b})$ and with adequate preincubation, sperm concentration would not appear to affect significantly the rate of penetration (this study, Series IV; Fukuda \& Chang, 1978a).

Many estimates of the intervals between sperm-egg fusion and the block to polyspermy have been made. For the mouse, Fukuda \& Chang (1978a, b), Wolf (1978) and Sato (1979) have suggested that the vitelline block occurs within $40 \mathrm{~min}$ after penetration; light and electron microscopic examination of fixed specimens in the present study suggest an interval of $<15 \mathrm{~min}$ (Table 3; Plates 1 \& 2). The synchrony observed in decondensation of the fertilizing sperm heads also suggests a rapid early blocking mechanism and, within 60-75 min of gamete mixing, it is possible to see supplementary spermatozoa moving within the perivitelline space of a fertilized egg.

Although zona-free eggs can be highly polyspermic initially, Yu \& Wolf (1981) have reported the eventual elimination of some penetrated spermatozoa. A similar phenomenon was observed in the present experiments when zona-free eggs were cultured for $4 \mathrm{~h}$, but this might be the response of the egg to the unnatural circumstance of being directly exposed to many spermatozoa and/or some trauma associated with zona removal. No similar decrease in the incidence of polyspermy in zonaintact eggs assessed chromosomally shortly after sperm penetration (14.9\%, Fraser \& Maudlin, $1979)$ or after 3 days culture $(12 \cdot 8 \%$, Fraser, Zanellotti, Paton \& Drury, 1976) has been detected.

In general, the conclusions reached on the morphological features of early sperm-egg interaction concur with those drawn in earlier studies; the primary difference lies in the accurate timing of the progression of fusion events. In agreement with Wolf \& Armstrong (1978), a flat orientation for the sperm head on the egg surface was observed (Pl. 1, Figs $2 \& 4$ ) and within $10 \mathrm{~min}$ egg cytoplasm thinly covered the head. Light and electron microscopic evaluation indicated that the initial interaction was limited to the posterior region of the head, progressing anteriorly until fusion had been completed (Pl. 1, Figs 1, 3 \& 5). Similar stages have been observed by Anderson, 
Hoppe, Whitten \& Lee 1975) and Thompson, Smith \& Zamboni (1974). In the latter study the equatorial segment could not be detected, but it was clearly visible and intact in specimens examined in the present study (see P1. 2, Fig. 8). When fertilization of hamster eggs occurred in vivo (Shalgi \& Phillips, 1980b), incorporation of the tip occurred last but with in-vitro fertilization (Shalgi \& Phillips, 1980a) the tip was incorporated first. Shalgi \& Phillips (1982) also reported initial incorporation of the tip region for rat spermatozoa in vitro and they suggest that this is abnormal. The findings of the present study indicate that mouse gamete interactions in vitro are similar to those described for hamster gametes in vivo. Although the fertilizing sperm head was usually located some distance from the large, microvilli-free area associated with the egg's meiotic apparatus, as reported by Nicosia, Wolf \& Inoue (1977), it was sometimes relatively close (P1. 1, Fig. 4).

In conclusion, the results presented here indicate that once fusion has been initiated, sperm head decondensation and egg progression through meiosis II occur rapidly and are completed within about $30 \mathrm{~min}$. These data reinforce the argument that rigorous examination of capacitation requires well-defined time limits for in-vitro fertilization systems.

I thank Dr Tony Brain and Mrs Chris LeBlond for their invaluable assistance in preparing the eggs for electron microscopy. This study was supported in part by a grant from the Marie Stopes Research Fund.

\section{References}

Anderson, E., Hoppe, P.C., Whitten, W.K. \& Lee, G.S. (1975) In vitro fertilization and early embryogenesis: a cytological analysis. J. Ultrastruct. Res. 50, 231-252.

Austin, C.R. (1961) The Mammalian Egg. Blackwell Scientific Publications, Oxford.

Bedford, J.M. (1970) Sperm capacitation and fertilization in mammals. Biol. Reprod., Suppl. 2, 128-158.

Donahue, R.P. (1972) Fertilization of the mouse oocyte: sequence and timing of nuclear progression to the two-cell stage. J. exp. Zool. 180, 305-318.

Florman, H.M. \& Storey, B.T. (1982) Mouse gamete interactions: the zona pellucida is the site of the acrosome reaction leading to fertilization in vitro. Devl Biol. 91, 121-130.

Fraser, L.R. (1977) Motility patterns in mouse spermatozoa before and after capacitation. $J$. exp. Zool. 202, 439-444.

Fraser, L.R. (1979) Rate of fertilization in vitro and subsequent nuclear development as a function of the post-ovulatory age of the mouse egg. J. Reprod. Fert. $55,153-160$.

Fraser, L.R. (1981) Dibutyryl cyclic AMP decreases capacitation time in vitro in mouse spermatozoa. $J$. Reprod. Fert. 62, 63-72.

Fraser, L.R. (1982a) p-Aminobenzamidine, an acrosin inhibitor, inhibits mouse sperm penetration of the zona pellucida but not the acrosome reaction. $J$. Reprod. Fert. 65, 185-194.

Fraser, L.R. (1982b) $\mathrm{Ca}^{2+}$ is required for mouse sperm capacitation and fertilization in vitro. J. Androl. 3, 412-419.

Fraser, L.R. \& Drury, L.M. (1975) The relationship between sperm concentration and fertilization in vitro of mouse eggs. Biol. Reprod. 13, 513-518.
Fraser, L.R. \& Maudlin, 1. (1979) Analysis of aneuploidy in first-cleavage mouse embryos fertilized in vitro and in vivo. Environ. Health Perspect. 31, 141-149.

Fraser, L.R., Zanellotti, H.M., Paton, G.R. \& Drury, L.M. (1976) Increased incidence of triploidy in embryos derived from mouse eggs fertilized in vitro. Nature, Lond. 260, 39-40.

Fukuda, Y. \& Chang, M.C. (1978a) Relationship between sperm concentration and polyspermy in intact and zona-free mouse eggs inseminated in vitro. Archs Androl. 1, 267-273.

Fukuda, Y. \& Chang, M.C. (1978b) The time of cortical granule breakdown and sperm penetration in mouse and hamster eggs inseminated in vitro. Biol. Reprod. 19, 261-266.

Meizel, S. (1978) The mammalian sperm acrosome reaction, a biochemical approach. In Development in Mammals, Vol. 3, pp. 1-64. Ed. M. H. Johnson. Elsevier-North Holland, Amsterdam.

Nicosia, S.V., Wolf, D.P. \& Inoue, M. (1977) Cortical granule distribution and cell surface characteristics in mouse eggs. Devl Biol. 57, 56-74.

Sato, K. (1979) Polyspermy-preventing mechanisms in mouse eggs fertilized in vitro. J. exp. Zool. 210, 353360 .

Shalgi, R. \& Phillips, D.M. (1980a) Mechanics of in vitro fertilization in the hamster. Biol. Reprod. 23, 433444.

Shalgi, R. \& Phillips, D. M. (1980b) Mechanics of sperm entry in cycling hamsters. J. Ultrastruct. Res. 71, 154161.

Shalgi, R. \& Phillips, D.M. (1982) Sperm penetration into rat ova fertilized in vitro. J. Androl. 3, 382-387.

Shams-Borhan, G. \& Harrison, R.A.P. (1981) Production, characterization and use of ionophore-induced, 
calcium dependent acrosome reaction in ram spermatozoa. Gamete Res. 4, 407-432.

Snedecor, G. \& Cochran, W. (1967) Statistical Methods, 6th edn. Iowa State University Press, Ames.

Thompson, R.S., Smith, D.M. \& Zamboni, L. (1974) Fertilization of mouse ova in vitro: an electron microscopic study. Fert. Steril. 25, 222-249.

Toyoda, Y., Yokoyama, M. \& Hosi, T. (1971) Studies on the fertilization of mouse eggs in vitro. II. Effects of in vitro pre-incubation of spermatozoa on time of sperm penetration of mouse eggs in vitro. Jap. J. Anim. Reprod. 16, 152-157.

Wolf, D.P. (1978) The block to sperm penetration of zona-free mouse eggs. Devl Biol. 64, 1-10.
Wolf, D.P. \& Armstrong, P.B. (1978) Penetration of the zona-free mouse egg by capacitated sperm: cinemicrographic observations. Gamete Res. 1, 3946.

Yanagimachi, R. (1970) The movement of golden hamster spermatozoa before and after capacitation. J. Reprod. Fert. 23, 193-196.

Yanagimachi, R. (1972) Fertilization of guinea pig eggs in vitro. Anat. Rec. 174, 9-20.

Yu, S.-F. \& Wolf, D.P. (1981) Polyspermic mouse eggs can dispose of supernumerary sperm. Devl Biol. 82, 203-210.

Received 22 December 1982 